\title{
ANÁLISE GENÉTICA DA HIBRIDAÇÃO EM GATOS
}

\author{
TINASI, Ana Luísa Santos Nielsen ${ }^{1}$ \\ COUTO, Leomam Almeida ${ }^{2}$ \\ COUTO, Cynthia MartinsVillar ${ }^{3}$
}

\begin{abstract}
RESUMO: Trabalho desenvolvido no Campus da Faculdade Dr. Francisco Maeda - FAFRAM, de Ituverava, SP., com o objetivo de elaborar um protocolo para análise da ocorrência de cruzamentos entre espécies de gatos doméstico e selvagem, além de buscar a confirmação científica dessa ocorrência, ainda não registrada no Brasil. Foram analisados os materiais genéticos de duas ninhadas de gatos com suspeita de serem resultado de cruzamento natural entre gatas domésticas com um gato selvagem. Para as análises, utilizou-se dois marcadores associados ao cromossomo Y, sendo eles o SMCY e o SRY, para identificação genética da linhagem paterna, e um marcador mitocondrial ATP6, para identificação da linhagem materna. Os resultados mostraram que os marcadores utilizados são adequados e suficientes para a confirmação ou exclusão da ocorrência de hibridação, tanto na linhagem paterna como na materna, podendo ser utilizado como protocolo para essas análises. Com o protocolo utilizado, concluiu-se que os animais em estudo pertencem à espécie doméstica (Felis silvestris catus), descartando qualquer possibilidade de hibridação com gatos selvagens da fauna brasileira.
\end{abstract}

Palavras-chave: Gato selvagem. DNA. Protocolo.

\section{GENETIC ANALYSIS OF HYBRIDIZATION IN CATS}

SUMMARY: This work was developed at Dr. Francisco Maeda - FAFRAM campus in the city of Ituverava, SP, aimed to elaborate a protocol for analysis of crossbreeding occurrence between domestic and wildcat species, and also to scientifically confirm this occurrence which still non-existent in Brazil. Genetic material of two litters of cats supposedly descending from natural crossing between domestic female cats and a male wildcat were analyzed. For such analysis, two markers associated with the Y chromosome were employed, SMCY and SRY, intending to identify the paternal lineage, and an ATP6 mitochondrial marker, to identify the maternal lineage. The results indicated that the used markers were adequate and sufficient to confirm or to exclude the occurrence of hybridization, in both paternal and maternal lineages, and could be used as protocol for such analysis. On the other hand, this work concluded that the animals belonged to the domestic cat species (Felis silvestris catus L.), discarding any possibility of hybridization with wildcats of the Brazilian fauna.

Keywords: Wild cat. DNA. Protocol.

\section{INTRODUÇÃO}

O gato doméstico (Felis silvestris catus; Linnaeus, 1758) acompanha o homem há milhares de anos. Existem divergências quanto à época da domesticação desses animais, variando

\footnotetext{
${ }^{1}$ Médica Veterinária pós graduanda em Clínica Médica e Cirúrgica de Pequenos Animais - Instituto Qualittas ${ }^{2}$ Doutor em Ciências pela Universidade Estadual de São Paulo (USP) e professor da Faculdade Dr. Francisco Maeda (FAFRAM)

${ }^{3}$ Doutora em Ciências com ênfase em Bioinformática pela Universidade Estadual de São Paulo (USP)
} 
de 10.000 a 2.500 anos atrás. Achados arqueológicos ao redor do mundo têm auxiliado na busca por uma data mais precisa mas nada se pode afirmar (TURNER; BATESON, 2000; VIGNE et al., 2004; MAGNABOSCO, 2006; DRISCOLL et al, 2007; O’BRIEN; JOHNSON, 2007; MELO, 2008; CLUTTON-BROCK, 2012).

O número crescente de gatos domésticos, associado ao aumento de ações antrópicas em áreas naturais e consequente fragmentação e perda de habitat dos animais selvagens, colocam em risco as populações de gatos selvagens brasileiros. No Brasil, registrou-se a presença de várias espécies selvagens de gatos de pequeno porte e já é comprovada a hibridação entre algumas delas (TRIGO et al, 2008; RUIZ-GARCÍA, M. et al., 2017). As espécies aqui encontradas são: Leopardus (Oncifelis) colocolo (Molina, 1782), Leopardus (Oncifelis) geoffroyi (d'Orbigny; Gervais, 1844), Leopardus guttulus (Hensel, 1872), Leopardus pardalis (Linnaeus, 1758), Leopardus tigrinus (Schreber, 1775) e Leopardus wiedii (Schinz, 1821) (REIS, 2006). Os limites geográficos se tornam mais vulneráveis e os cruzamentos entre diferentes espécies ocorrem devido a um complexo desequilíbrio ecológico (OLIVEIRA, R., 2012).

Atualmente, existem suspeitas de que o ser humano esteja acelerando esse processo de hibridação com as ações que promove no meio ambiente (GANDRA, 2007; COSTA, 2018). A pecuária extensiva associada às grandes plantações têm destruído o habitat de inúmeras espécies. As queimadas, a construção de rodovias, o crescimento populacional que por sua vez faz com que as cidades se ampliem, juntamente com outras atividades antrópicas, estão modificando o meio ambiente. Com isso, os animais estão perdendo espaço e têm seus nichos ecológicos afetados, fazendo com que a alimentação e reprodução fiquem seriamente comprometidas (OLIVEIRA R., 2012).

Diante dessa realidade, as espécies felinas buscam alternativas, instintivamente, afim de continuarem a transmitir seu material genético. Uma dessas alternativas, visto que as espécies estão se extinguindo, é a ocorrência dos cruzamentos entre espécies distintas, resultando portanto, nos animais híbridos (OLIVEIRA R., 2012).

Acreditava-se que o cruzamento entre diferentes espécies só gerava descendentes estéreis, mas já sabe-se que é possível que o processo de hibridação gere descendentes férteis (FIORAVANTI, 2011).

A ocorrência de cruzamentos entre diferentes espécies de felídeos vem sendo estudada no Brasil e já mostra resultados interessantes. Segundo Trigo et al. (2008), há zonas de hibridação entre Leopardus tigrinus, e Leopardus geoffyoyi no Estado do Rio Grande do Sul. Estima-se que cerca de $60 \%$ da população de felídeos selvagens nesse local seja de origem híbrida. O estudo também confirma a ocorrência de cruzamento entre as espécies Leopardus tigrinus e Leopardus colocolo no centro e no nordeste do país. A análise genética dos animais foi feita a partir de 
marcadores moleculares como DNA mitocondrial, segmentos dos cromossomos X e Y e locos de microssatélite. Os resultados obtidos a partir do estudo relatado agrega informações valiosas a respeito do crescimento constante de variabilidade genética além de questionar os limites ecológicos e geográficos.

A ocorrência de cruzamentos entre gatos domésticos e gatos selvagens é conhecida em diversas partes do mundo (PIERPAOLI, 2003; OLIVEIRA, R. 2012; NEAVES; HOLLINGSWORTH, 2013). No entanto, no Brasil, ainda não há comprovação científica de cruzamentos entre gatos domésticos e gatos selvagens brasileiros, apesar de aceito como fato pela população, especialmente do meio rural. (informação verbal) ${ }^{4}$.

Os cruzamentos entre gatos domésticos (Felis silvestris catus) e gatos selvagens são uma ameaça para a perpetuação dessa espécie. Conservar e proteger os gatos selvagens é de extrema importância para sua sobrevivência mas muito difícil de se realizar devido à dificuldade de se identificar a hibridação a campo (BALLESTEROS-DUPERÓN, 2015).

A partir dessas considerações, os objetivos do presente trabalho foram verificar a ocorrência natural de cruzamentos entre o gato doméstico e espécies selvagens da fauna brasileira, através de análise do material genético de gatos provenientes de duas ninhadas, nas quais há suspeita de cruzamento interespecífico e desenvolver um protocolo para análise dessa ocorrência. A confirmação genética da existência desse híbrido expandirá o conhecimento sobre limites de interação interespecífica, abrindo caminhos para a identificação de novas espécies.

\section{MATERIAL E MÉTODOS}

Na região rural de Ituverava, SP, obteve-se acesso a duas ninhadas de gatos, provindas, segundo relato do proprietário dos animais, de cruzamentos entre suas gatas domésticas sem raça definida e um gato-do-mato, visitante frequente de sua propriedade, provavelmente pertencente à espécie Leopardus guttulus devido à localização que se encontra. As ninhadas produzidas eram compostas de nove filhotes no total, sendo seis machos e três fêmeas. Os animais foram acompanhados durante o seu desenvolvimento, período no qual foram coletados dados relativos a esse estudo e posteriormente foram doados. Todos os animais foram vacinados e vermifugados antes da doação.

Os animais foram mantidos em uma baia nas dependências do Hospital Veterinário da Faculdade Dr. Francisco Maeda - FAFRAM, de Ituverava/SP, com dimensões de $5 \mathrm{~m}$ x 4m, com $3 \mathrm{~m}$ de altura, adaptada como gatil. Os animais foram visitados diariamente, fazendo parte da rotina deles, portanto, a interação e a sociabilização.

\footnotetext{
${ }^{4}$ Informação fornecida por prof. Dr. Leomam Almeida Couto.
} 
O espaço foi preparado e enriquecido ambientalmente para receber os animais, baseado em pesquisas sobre ambientação felina, com o intuito de incentivar comportamentos naturais da espécie, reduzir comportamentos de estresse e aumentar a interação positiva intraespecífica (ELLIS, 2009; OLIVEIRA A., 2012).

Além do enriquecimento ambiental, salientado com bolas de papel e de borracha, com e sem guizo, barbantes, garrafas plásticas, cordas de sisal, troncos de árvores e caixas de papelão, os animais receberam ração de boa qualidade (seca e úmida) e água fresca.

O projeto de pesquisa detalhado foi encaminhado à apreciação da Comissão de Ética no Uso de Animais (CEUA) da Faculdade Dr. Francisco Maeda, que emitiu parecer aprovando os procedimentos propostos no projeto, sob protocolo n. 05/2015.

\section{COLETA SANGUÍNEA E LOCAL DAS ANÁLISES}

Aos quatro meses de idade, uma amostra de sangue de cada animal foi coletada para realização das análises genéticas. O sangue foi coletado a partir de punção da veia cefálica de cada animal, utilizando-se seringa e agulha descartáveis. Para definir a espécie dos animais do estudo, é necessário conhecer o padrão genético do gato doméstico (Felis silvestris catus) e do gato-do-mato em questão, Leopardus guttulus. Sendo assim, coletou-se o sangue de um gato doméstico, para controle. Quanto ao material genético de Leopardus guttulus, o Laboratório de Biodiversidade Molecular e Conservação da Universidade Federal de São Carlos, para onde o material foi enviado, já possuía amostras armazenadas dessa espécie.

O sangue coletado foi devidamente estocado em frascos eppendorf esterilizados de $1 \mathrm{~mL}$, contendo álcool 70\%. Cada eppendorf foi identificado com o nome do animal, resfriado e enviado ao referido laboratório para extração do DNA, amplificação e análise. Posteriormente, as amostras de DNA purificadas e amplificadas foram enviadas para leitura em laboratório de análises genéticas na Coréia do Sul.

\section{EXTRAÇÃO E ANÁLISE DE DNA}

A extração do DNA das amostras de sangue foi realizada seguindo o protocolo de extração por tampão salino proposto por Aljanabi; Martinez (1997) com algumas adaptações:

1. Homogeneizar o sangue $(50$ a $100 \mu \mathrm{l})$ em $400 \mu \mathrm{l}$ de tampão salino $(\mathrm{NaCl} 0,4 \mathrm{M}$; Tris $\mathrm{HCl} 10$ mM pH 8,0 e EDTA pH 8,0 a 2 mM).

2. Adicionar $40 \mu \mathrm{l}$ de SDS $20 \%$ e $15,0 \mu \mathrm{l}$ de Proteinase $\mathrm{K} 20 \mathrm{mg} / \mathrm{ml}$ e misturar bem.

3. Incubar as amostras a $55-65^{\circ} \mathrm{C}$ por pelo menos $2 \mathrm{~h}$ ou overnight. 
4. Adicionar $300 \mu \mathrm{l}$ de $\mathrm{NaCl} 6 \mathrm{M}$.

5. Vortexar as amostras por 30 segundos a velocidade máxima e centrifugar por $30 \mathrm{~min}$. a $10000 \mathrm{rpm}$.

6. Transferir o sobrenadante para outro tubo $(1,5 \mathrm{ml})$.

7. Adicionar igual volume de isopropanol e misturar bem.

8. Incubar a $-20^{\circ} \mathrm{C}$ por $1 \mathrm{~h}$ ou $-80^{\circ} \mathrm{C}$ por $20-30 \mathrm{~min}$.

9. Centrifugar por $20 \mathrm{~min}$. a $10000 \mathrm{rpm}$.

10. Lavar o pellet com $300 \mu \mathrm{l}$ de etanol $70 \%$ e centrifugar por 5 minutos.

11. Lavar o pellet novamente com $300 \mu \mathrm{l}$ de etanol $100 \%$ e centrifugar por mais $5 \mathrm{~min}$.

12. Secar o DNA em estufa e ressuspender em $100 \mu \mathrm{l}$ de $\mathrm{H}_{2} \mathrm{O}$. Caso haja necessidade, colocar RNAse $(2,0 \mu \mathrm{l}$ a uma concentração de $10 \mathrm{ng} / \mu \mathrm{l})$.

Após a extração, o DNA foi quantificado em Biofotômetro (BioPhotometer, Eppendorf®) e alíquotas com concentrações de $50 \mathrm{ng} / \mu \mathrm{l}$ foram preparadas para uso nas Reações em Cadeia da Polimerase (Polimerase Chain Reaction, PCR).

\subsection{Amplificação dos marcadores}

Para verificar e confirmar a origem dos possíveis indivíduos híbridos, foram selecionados três marcadores para as análises genéticas. Entre os marcadores, foi selecionado um marcador mitocondrial (ATP6) utilizando os primers ATP6-DF3 e ATP6-DR2 descritos por Chaves et al. (2012) com os quais confirmamos a espécie da mãe dos indivíduos. Em seguida, foram selecionados dois marcadores associados ao cromossomo Y para determinar a espécie do pai dos indivíduos: SMCY, utilizando os primers SMCY3-DF1 e SMCY3-DR1 descritos por (Trigo et al., 2013); e o gene SRY utilizando os primers SRY-F e Lut-SRy descrito por Dallas et al. (2000).

O protocolo de amplificação para o ATP utilizado foi: cada PCR contém um volume total de $15 \mu 1$, com 3 a $5 \mu 1$ de DNA estoque, $0,15 \mathrm{mM}$ de dNTP, 1x de tampão 10x, 2 a 2,5mM de Cloreto de Magnésio (Invitrogen ${ }^{\circledR)}$ ), 150 $\mu \mathrm{g} / \mathrm{ml}$ de BSA, 1,0 $\mu \mathrm{M}$ de cada primer e uma unidade de Taq DNA polimerase (Platinum, Invitrogen $®)$. O ciclo estabelecido no termociclador foi: desnaturação inicial a $94^{\circ} \mathrm{C}$ por $5 \mathrm{~min}$, seguido por $94^{\circ} \mathrm{C}$ por $45 \mathrm{seg}$., $60^{\circ} \mathrm{C}$ por $45 \mathrm{seg}$. (com touchdown até $50^{\circ} \mathrm{C}$ ) e $72^{\circ} \mathrm{C}$ por $1,5 \mathrm{~min}$, em seguida, 35 ciclos de $94^{\circ} \mathrm{C}$ por $5 \mathrm{~min}, 94^{\circ} \mathrm{C}$ por 45 seg., $50^{\circ} \mathrm{C}$ por $45 \mathrm{seg} ., 72^{\circ} \mathrm{C}$ por $1,5 \mathrm{~min}$ e extensão final a $72^{\circ} \mathrm{C}$ por $10 \mathrm{~min}$.

Para os marcadores SMCY e SRY usamos os protocolos de amplificação descritos por Trigo et al. (2013) e Dallas et al. (2000), respectivamente. Após a amplificação, todos os produtos de PCR foram visualizados em gel de agarose 1\%, purificados com a enzima ExoSAP- 
IT (Affymetrix) e enviados para sequenciamento em sequenciador ABI3730XL, Applied Biosystems.

\subsection{Análise dos dados}

As sequências obtidas foram visualizadas e editadas no software Geneious v. 7.1.7 (KEARSE et al., 2012). Após a checagem das sequências e alinhamento das mesmas, foram calculadas as distâncias genéticas entre as sequências obtidas e sequências de referência através do programa MEGA v.5.03 (TAMURA et al., 2011), utilizando o Modelo de Dois Parâmetros de Kimura (1980). Posteriormente, realizou-se a análise de Neighbor-Joining (SAITOU; NEI, 1987). A significância estatística foi avaliada pelo método de bootstrap com 1000 replicações.

\section{RESULTADOS FINAIS}

O DNA foi extraído com sucesso em todas as amostras e também obteve-se sucesso na amplificação das regiões dos três genes selecionados.

Os resultados das análises das sequências gênicas dos animais em estudo foram comparados, considerando as sequências genéticas do gato doméstico (Felis silvestris catus) e do gato-do-mato-pequeno (Leopardus guttulus), que se tem como suspeito de ser a espécie do pai dos supostos híbridos. Inicialmente se comparou o DNA mitocondrial, herdado pelos animais somente da linhagem materna, para a caracterização genética da mãe dos animais.

A partir da análise da figura abaixo (Figura 1), usando o método de comparação NeighborJoining Saitou; Nei, (1987), pode-se observar na árvore filogenética que as sequências do marcador ATP6, provindas de DNA mitocondrial dos animais do estudo apresentam uma ramificação distinta, com distância significativa das sequências dos animais selvagens (Leopardus guttulus) e proximidade da sequência do gato doméstico (Felis silvestris catus) utilizado como controle (H11). Este resultado permite-nos concluir que as mães dos animais de ambas as ninhadas em estudo são gatas domésticas. 
Figura 1: Árvore Neighbor-Joining das sequências do marcador mitocondrial ATP6.

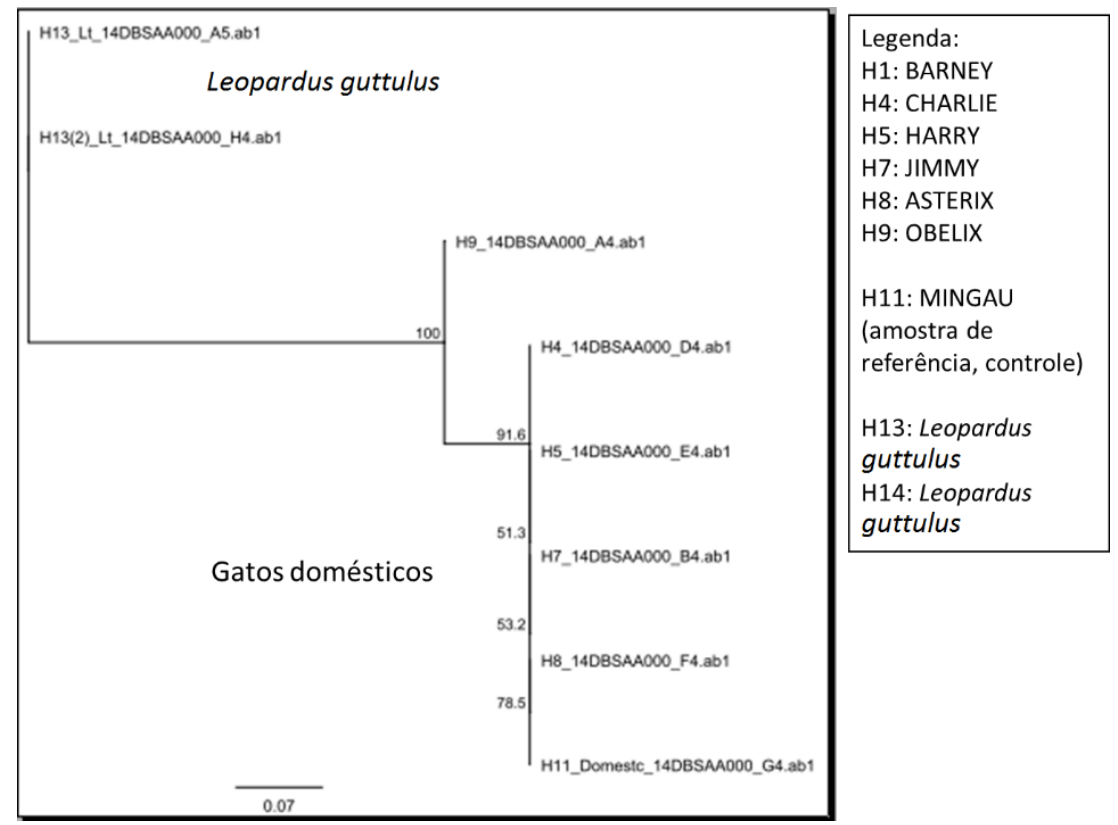

Fonte: Laboratório de Biodiversidade Molecular e Conservação da UFSCar, 2016

As figura 2 e figura 3 apresentam os resultados genéticos na forma de árvore filogenética, relativas às análises das sequências dos genes SMCY e SRY associados ao cromossomo Y, portanto herdados somente do pai. A figura 2 mostra que o marcador SMCY inclui sequências dos animais teste que não variam muito em relação às sequências ortólogas em Leopardus guttulus, o que gerou necessidade de confirmação da similaridade filogenética a partir da análise de outro loci. A figura 3 permite concluir que as sequências do marcador SRY dos animais do estudo, assim como as do gene ATP6 (de DNA mitocondrial), se distanciam significativamente das sequências dos animais selvagens, Leopardus guttulus. Por outro lado, são mais próximas geneticamente à sequência do animal H11 (gato doméstico utilizado como controle). Portanto, os resultados dos marcadores associados ao cromossomo Y determinam que o pai dos animais em estudo não é uma espécie selvagem (L. guttulus), mas sim um gato doméstico, como pode ser visto abaixo. 
Figura 2 Árvore Neighbor-Joining das sequências do marcador associado ao cromossomo Y, SMCY.

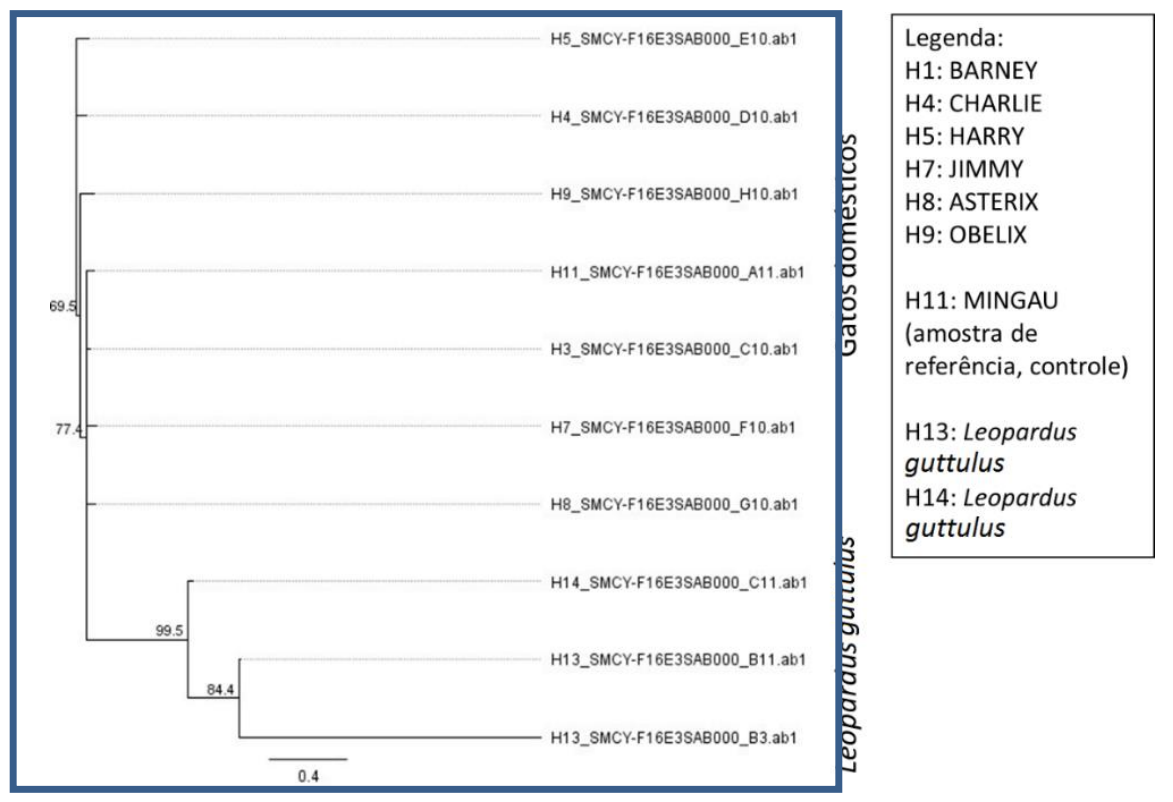

Fonte: Laboratório de Biodiversidade Molecular e Conservação da UFSCar, 2016

Figura 3 Árvore Neighbor-Joining das sequências do marcador associado ao cromossomo Y, SRY

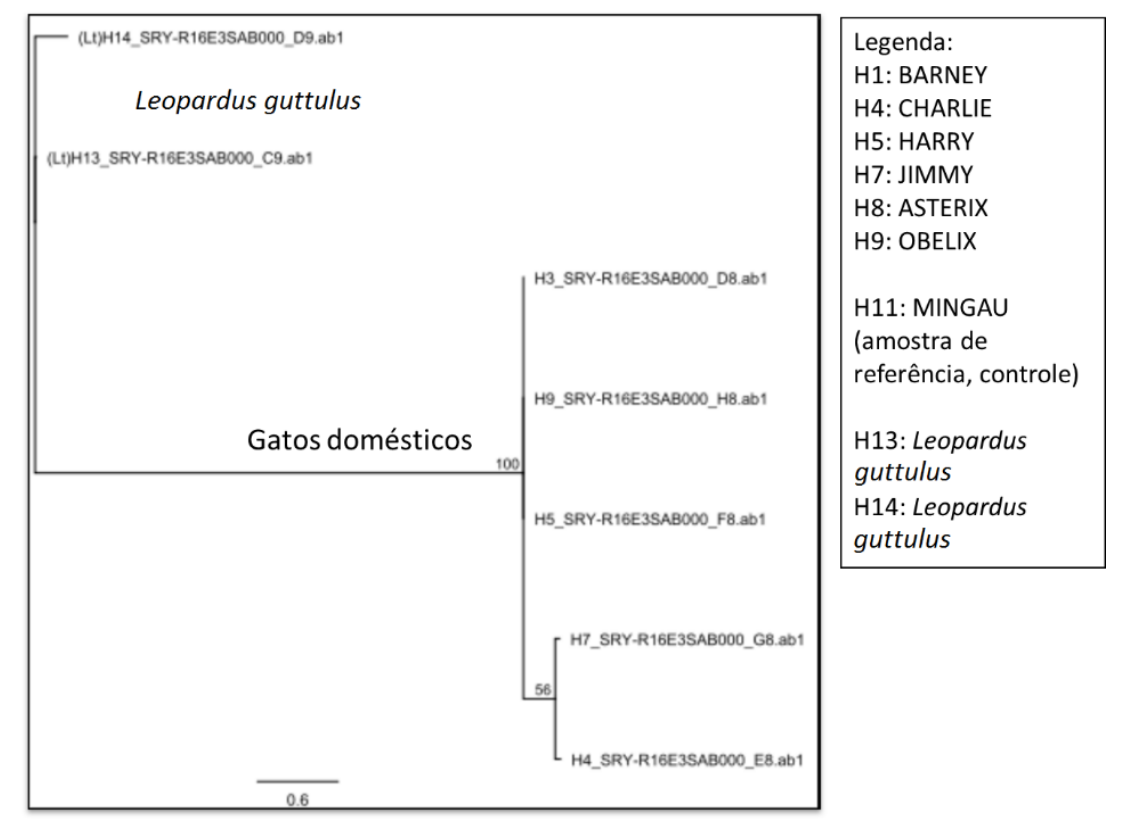

Fonte: Laboratório de Biodiversidade Molecular e Conservação da UFSCar, 2016

Analisando todos os resultados das sequências gênicas comparadas nesse experimento, podemos concluir, com segurança, que os animais das ninhadas estudadas não são híbridos. Portanto, apesar dos relatos do proprietário das gatas, que sugeria a ocorrência de cruzamentos entre estas fêmeas e um gato-do-mato, o evento não ocorreu, ou se ocorreu, não foi efetivo na fecundação. 
Isso mostra que, em termos científicos, ainda não existe comprovação da ocorrência de hibridação entre gatos selvagens e gatos domésticos no Brasil, diferentemente do que já foi constatado em outros países. Em Portugal, Oliveira R., (2012) demonstrou a ocorrência de cruzamento entre gatos domésticos e gatos selvagens europeus (Felis silvestris silvestris). Segundo Pierpaoli, (2003), há presença de hibridação em Portugal, Itália, Bulgária, Hungria e Escócia. Concordando com Pierpaoli, (2003), Neaves; Hollingsworth, (2013), em seu estudo também confirmaram a presença do cruzamento entre gatos domésticos e selvagens na Escócia.

\section{CONSIDERAÇÕES FINAIS}

As análises de DNA realizadas nos animais de ambas as ninhadas avaliados nesse estudo, demonstram claramente que não são híbridos, ou seja, os animais pertencem à espécie Felis silvestris catus, L. (gato-doméstico).

Os marcadores genéticos utilizados nesse estudo foram adequados e suficientes para a confirmação genética, tanto da espécie da linhagem materna (marcador mitocondrial ATP6), como da espécie da linhagem paterna (marcadores SMCY e SRY), podendo ser utilizados como protocolo padrão para a confirmação ou exclusão inicial da ocorrência de hibridação entre gatos domésticos e selvagens.

A comprovação da ocorrência de cruzamento do gato doméstico (Felis silvestris catus, L.) com gatos selvagens continua sem registros científicos, no Brasil.

\section{AGRADECIMENTOS}

Ao Bruno Henrique Saranholi, doutor em Genética com ênfase em Diversidade Genética de Felinos pela Universidade Federal de São Carlos (UFSCar) e ao Pedro Manoel Galetti Junior, PHD em Ecologia pela Universidade Federal de São Carlos (UFSCar) e professor titular do Departamento de Genética e Evolução da UFSCar, pelo acolhimento e empenho durante a execução do projeto.

\section{REFERÊNCIAS}

ALJANABI, S.M.; MARTINEZ, I. Universal and rapid salt-extraction of high quality genomic DNA for PCR-based techniques. Nucl. Acid. Reseach, v. 25, n. 22: p. 4692-4693, 1997.

BALLESTEROS-DUPERÓN, E. et al. How accurate are coat traits for discriminating wild and hybrid forms of Felis silvestris? Mammalia, v. 79, n. 1, p. 101-110, 2015. 
CHAVES, P. B. et al. DNA barcoding meets molecular scatology: short mtDNA sequences for standardized species assignment of carnivore noninvasive samples. Molecular Ecology

Resources, v. 12, n.1, p. 18-35, 2012.

COSTA, R. P. V. Identification of SNPs in genes potentially affected by domestication to efficiently detect hybridization between wild and domestic cats. 2018. Tese de Doutorado.

CLUTTON-BROCK, J. Animals as domesticates: a world view through history. MSU Press, 2012. 240p.

DALLAS, J. F. et al. Sex identification of the Eurasian otter Lutra lutra by PCR typing of spraints. Conservation Genetics. v. 1, n.2, p. 181-183, 2000.

DRISCOLL, C. A. et al. The near eastern origin of cat domestication. Science, v. 317, n. 5837, p. 519-523, 2007.

ELLIS, S. L. Environmental enrichment: practical strategies for improving feline welfare.

Journal of feline medicine and surgery, v. 11, n. 11, p. 901-912, 2009.

FIORAVANTE, C. Quando os híbridos são férteis. Evolução. Pesquisa Fapesp. Julho, 2011.

Disponível em: http://revistapesquisa.fapesp.br/wp-content/uploads/2011/07/060-063-

185.pdf?bc93e6. Acesso em 14 out. 2016.

GANDRA, C. Hibridação. Mundo dos animais. n. 2, p. 22-43 , 2007.

KEARSE, M. et al. Geneious Basic: an integrated and extendable desktop software platform for the organization and analysis of sequence data. Bioinformatics, v. 28, n. 12, p. 1647-1649, 2012.

KIMURA, M. A simple method for estimating evolutionary rates of base substitutions through comparative studies of nucleotide sequences. Journal of Molecular Evolution. v. 16, n. 2, p. 111-120, 1980.

MAGNABOSCO, C. População domiciliada de cães e gatos em São Paulo: perfil obtido através de um inquérito domiciliar multicêntrico. 2006. Tese de Doutorado. Universidade de São Paulo.

MELO, S. B. F. de. O gato doméstico (Felis catus) responde à sinais gestuais? possíveis implicações do convívio social. 2008. Tese de Mestrado. Univerdade Federal do Rio Grande do Norte.

NEAVES, L. E.; HOLLINGSWORTH, P. M. The Scottish wildcat (Felis silvestris). A review of genetic information and its implications for management. Conservation Genetics Knowledge Exchange, Royal Botanic Garden Edinburgh. 2013

O'BRIEN, S. J.; JOHNSON, W. E. The evolution cats. Scientific American, v. 297, n. 1, p. 68$75,2007$.

OLIVEIRA, A. S. Uso do espaço por gatos confinados: o papel modulatório do enriquecimento ambiental. 2012. Tese de mestrado. Universidade de São Paulo.

OLIVEIRA, R. I. R. M. Towards a wide genetic approach for the European wildcat [Felis silvestris silvestris] conservation: improving noninvasive molecular techniques, population analysis and admixture inferences. 2012. Tese de doutorado. Universidade do Porto, Portugal. 
PIERPAOLI, M. et al. Genetic distinction of wildcat (Felis silvestris) populations in Europe, and hybridization with domestic cats in Hungary. Molecular Ecology, v. 12, n. 10, p. 2585-2598, 2003.

REIS, N R dos P et al. Mamíferos do Brasil. Londrina, 2006. 437p.

RUIZ-GARCÍA, M. et al. Small spotted bodies with multiple specific mitochondrial DNAs: existence of diverse and differentiated tigrina lineages or species (Leopardus spp: Felidae, Mammalia) throughout Latin America. Mitochondrial DNA Part A, p. 1-22, 2017.

SAITOU, N.; NEI, M. The neighbor-joining method: a new method for reconstructing phylogenetic trees. Molecular Biology and Evolution. v. 4, n. 4, p. 406-425, 1987

TAMURA, K. et al. MEGA5: molecular evolutionary genetics analysis using maximum likelihood, evolutionary distance, and maximum parsimony methods. Molecular Biology and Evolution. v. 28, n. 10, p. 2731-2739, 2011.

TRIGO, T. C et al. Molecular data reveal complex hybridization and a cryptic species of Neotropical wildcat. Current Biology, v. 23, n.24, p. 2528-2533, 2013.

TRIGO, T. C. et al. Inter-species hybridization among neotropical cats of the genus Leopardus, and evidence for an introgressive hybrid zone between L. geoffroyi and L. tigrinus in southern Brazil. Molecular Ecology. v. 17, n. 19, p. 4.317- 4.333. out. 2008.

TURNER D. C.; BATESON P. The domestic cat: the biology of its behavior. In: SERPELL, J. A. Domestication and history of the cat. 2000. p.83-101.

VIGNE, J. D. et al. Early taming of the cat in Cyprus. Science, v. 304, n. 5668, p. 259-259, 2004. 